\title{
دراسة اثر تطور الات الحفر ثلاثية الابعاد علي البناء النحتي والابداع \\ المعاصر
}

Study the impact of the development of three dimensional carving machines on the construction of sculpture and contemporary creativity



بقسم التعبير المجسم كلية التزبية الفنية - جامعة حلوان البطان استاذ النحت بقسم التزبية الفنية - جامعة السلطان قابوس لكران

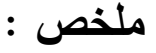

يحقق النطور التكنولوجي حاجة الصناعة للانتاج السريع والدقيق في تخصصات تميزت باللمسة الانسانية كالتتكيل النحتى، وهو ما اوجد محاور متعددة لانتاج ماكينات الحفر

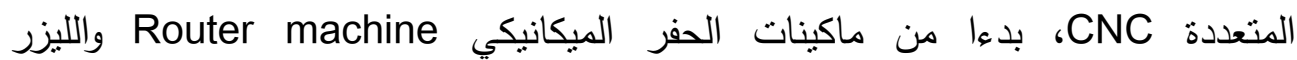

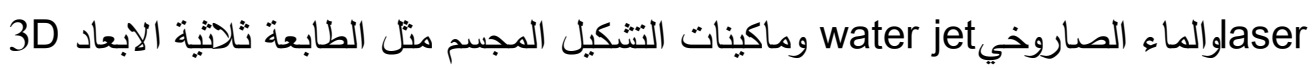

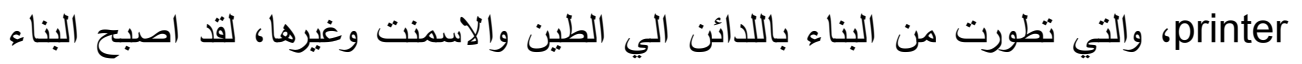

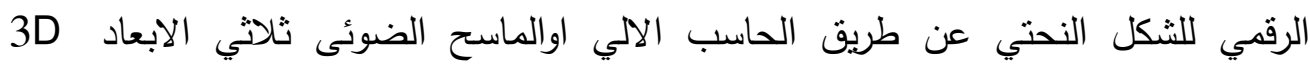
Scanner



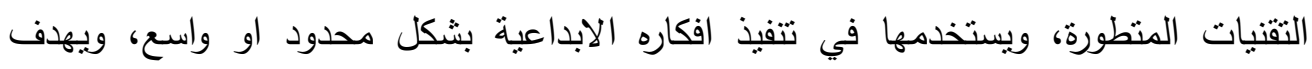

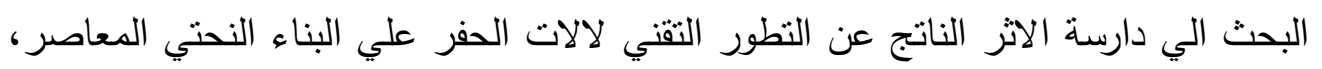

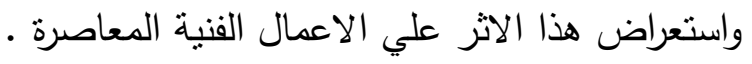




\section{Abstract:}

The technological development achieves the need of the industry for quick and accurate production and in specializations characterized by human touch, such as sculptural expression, which has created multiple axes for the production of CNC carving machines, starting with mechanical Router machine, laser, water jet machines and construction machines such as 3D printer which developed from construction of plastic to clay and Concrete „Has become the digital construction of the shape of the sculpture computer or the 3D Scanner is the entrance to the digital form, which was associated with the Automatic construction, which meets the requirements of the industry fast and accurate and differs from the human manual construction of the sculptor, which has become The research aims to study the effect of the technical development of the carving machines on the contemporary sculpture construction and reviewed these contemporary works of sculpture. 
ارتبط فن النحت بالجانب المادي من حياة الانسان، فتعامل مع الاسطح والحجوم وذلك

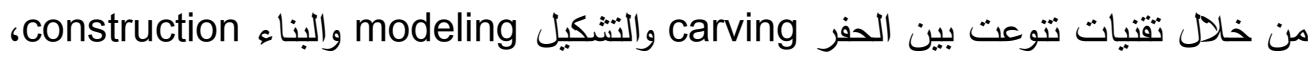
وهو ما ظهر واضحا في تراث الحضارات القديمة وامتد الي الحياة المعاصرة، فلا يخلو مجال

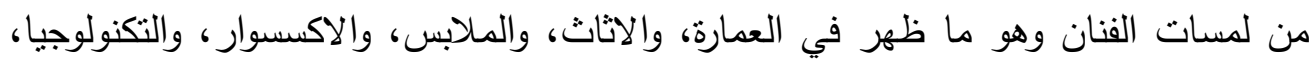

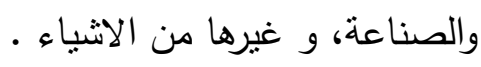

فالتشكيل مرتبط بالخامة وهو ما يطول الجانب المادي من حياتتا، فلا يمكن حصر ما ها

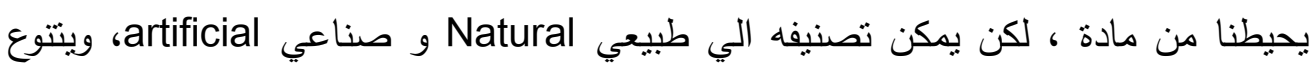


تتخل في التشكيل كوسبط تعبيري . النحت احد مجالات الفن النتكيلي الذى ارتبطت بالتشكيل ثلاثي الابعاد - Three dimensional

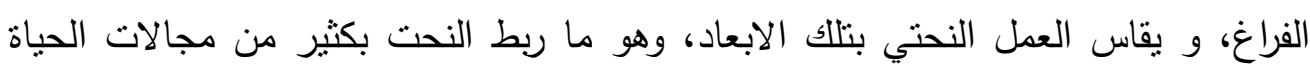


تقوم الصناعة علي محاور متعددة، منها ما يقوم علي تجهيز الخامات الاولية، واخرى بندي

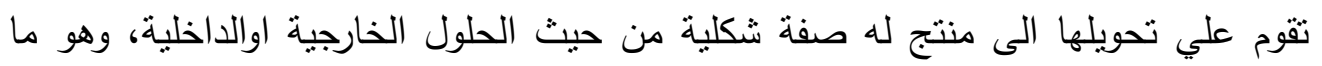
يتطلب تشكيل برتبط بالنحت، كما يستخدم القالب النحتى في الاستتساخ الكمي.


امكن نوفير مصدر ادق من الايدي البشرية، ووقت يتتاسب مع متطلبات الانتاج، كما استفاد

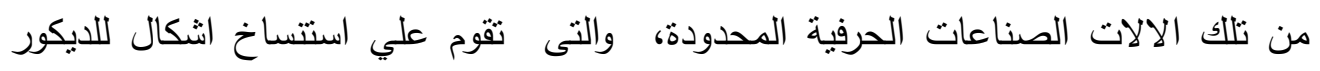

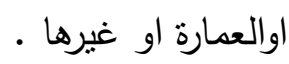

يهدف البحث الى استعرض تطور الات التشكيل ثلاثنية الابعاد، لما لها من مردود هام

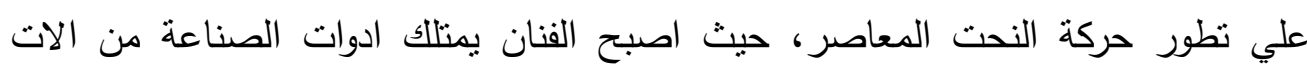
محدودة الحجم و ذات امكانات فعالة، تسمح له ان يتوسع في تطبيقاته الفنية، مستغلا الدقة

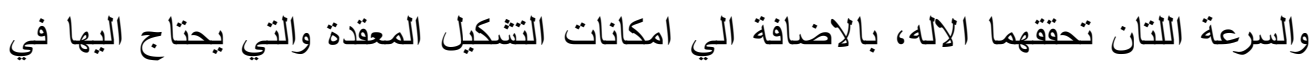

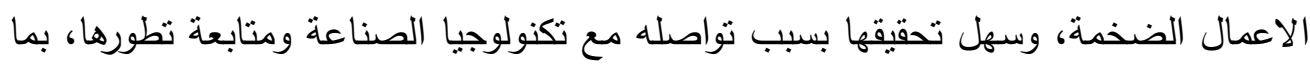

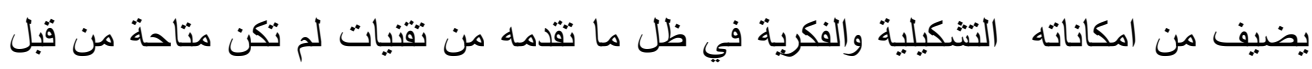
مثل التتكيل الداخلى، والتي امكن تحقيقها من خلال الطابعة ثلاثية الابعاد . 
تحتاج مجالات صناعية عديدة للنحت كما في صناعة الاثاث الخشبي، ومكملات الحدائق الحجرية، وسباكة المعادن، وهي صناعة اعتمدت علي التقنيات اليدوية في مراحلها الاولى، وتطورت مع تطور الات الحفر .

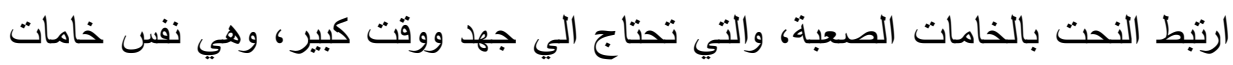
الصناعة، مع اختلاف واضح بين التشكيل الذي ينحصر في نسخة واحدة او نسختين وبين

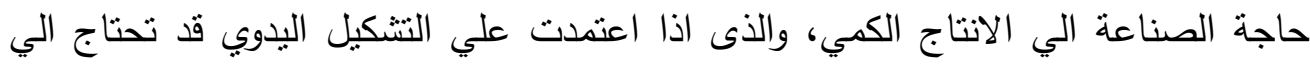
مئات النحاتين، و هي من المشكلات الاساسية التى ادت الى تطوير الات التشكيل ثالاثية التئي

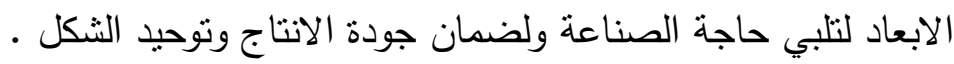

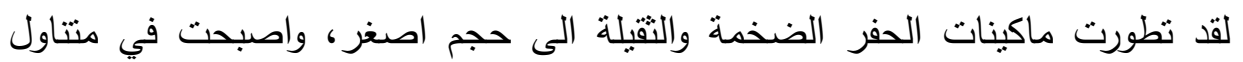
الفنانين والحرفين، و تتوعت في اساليب التشكيل، فمنها ما يعتمد علي نموذج اولي يتم

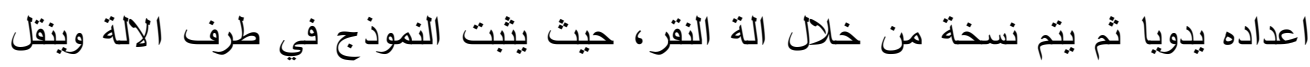

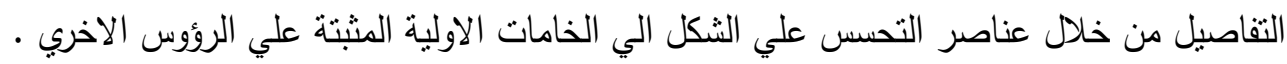

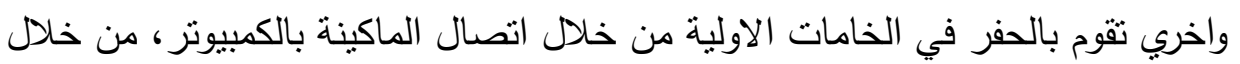

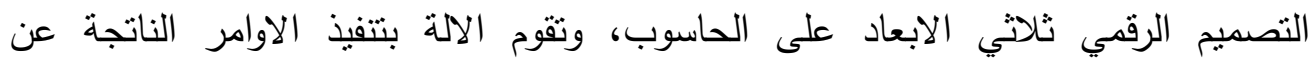

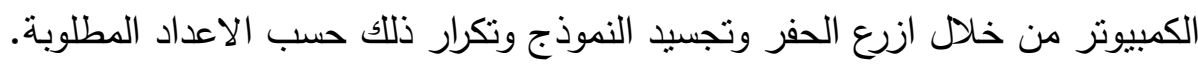

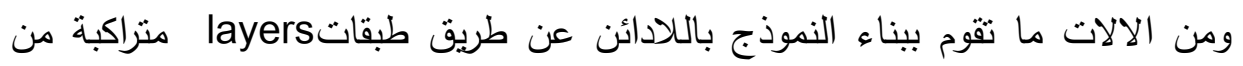
اسفل الي اعلي حتى يكتمل الثكل، وهي تتصل بالحاسوب وتتفذ الاوامر وتستخدم في بناء

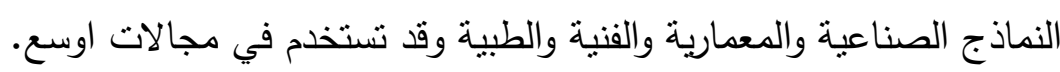

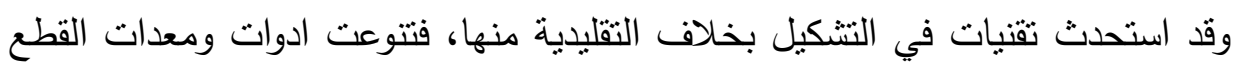


water jet ، قطع بلازما Plasma Cutting وغيرها، كما نطورت معدات الثني والتجميع واللحام.

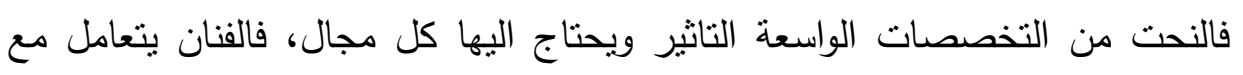

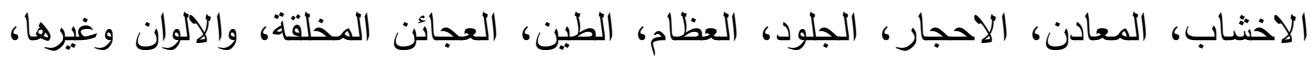
فكل خامة تتطلب نشاط محدد حسب المجال، كما تتعدد الاساليب والمهارات . 

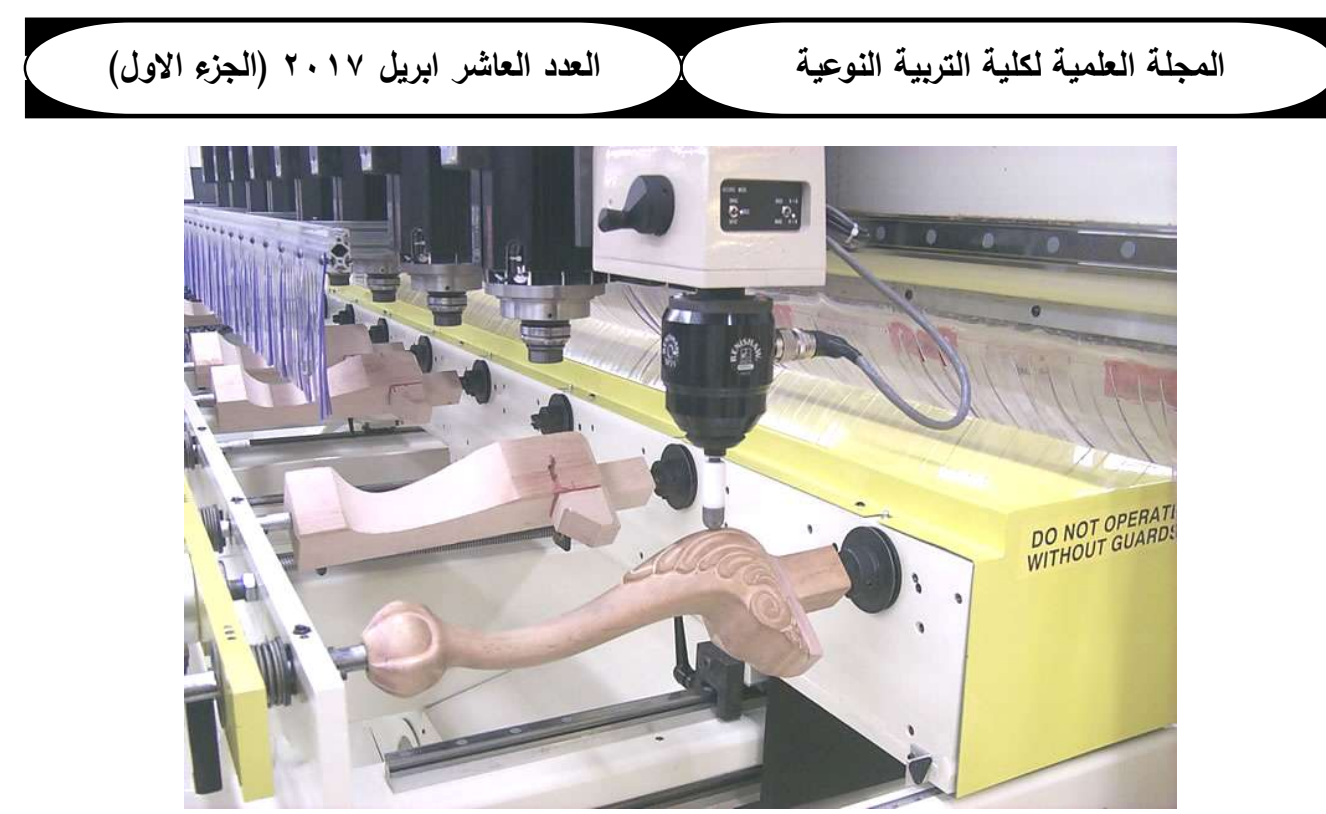

ماكينة نقرحفر راوثر ثلاثية الابعاد ذات رؤوس متعددة للاستتساخ العددي


ماكينة حفر راوتر متصلة بالحاسوب 


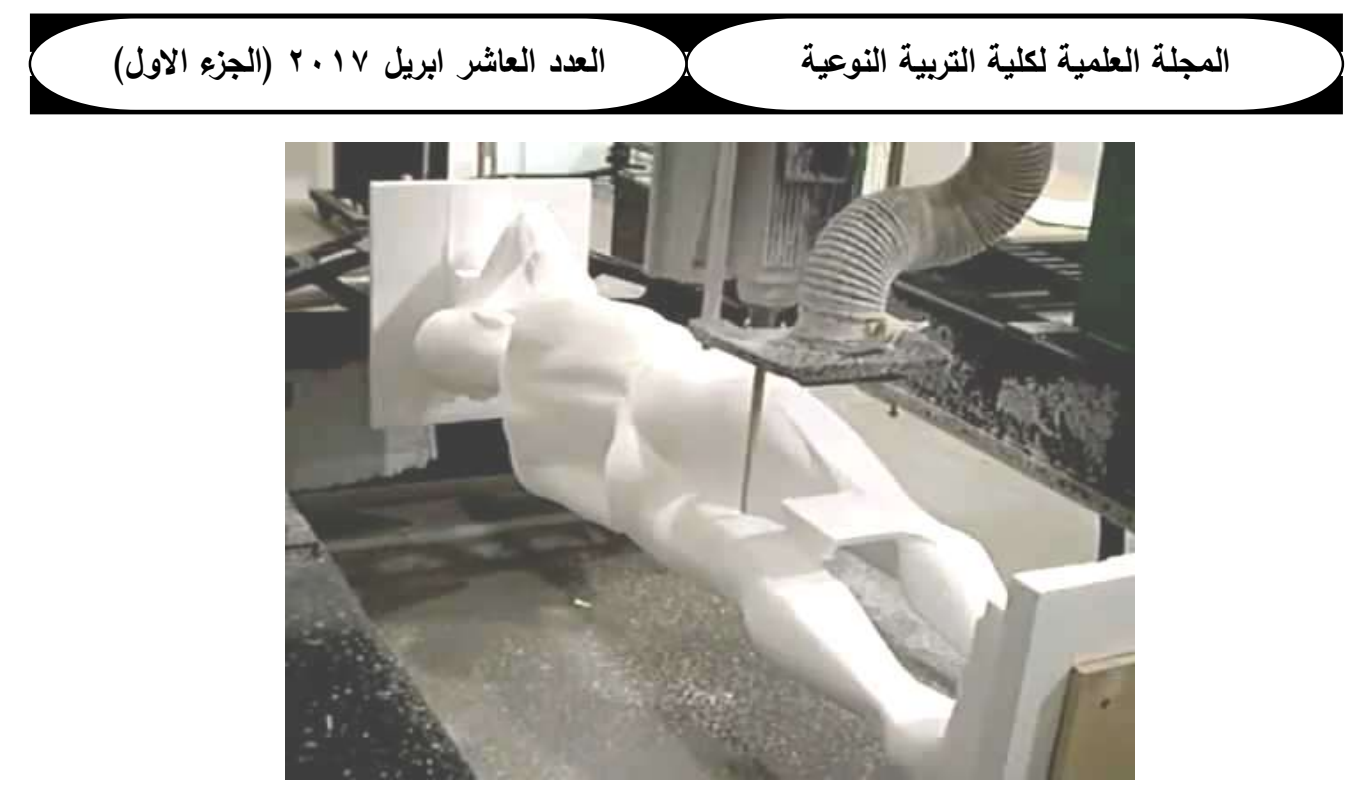

ماكينة حفر ميكانيكى ثلاثية الابعاد للحفر علي العديد من الخامات

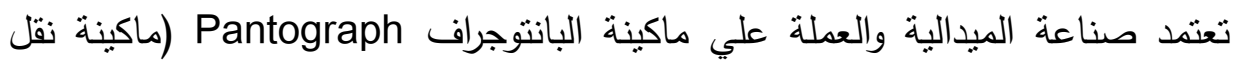
الرسوم والمجسمات) حيث يتم عمل النموذج الاساسي من قبل النحات ويثبت قالب الثكل في الالة ويحدد المقاس المطلوب وتقوم الالة بحفر نفس التفاصيل في خامة الصلب وبالنسب • المطلوبة للتصغير

وبعد انتهاء عمل الالة يصبح عندنا قالب من الصلب، يمكن النسخ من خلاله اعداد

كبيرة لثكل الميدالية اوالعملة بالحجم الذي نريده، و هي من التقنيات القديمة في صناعة العملة .

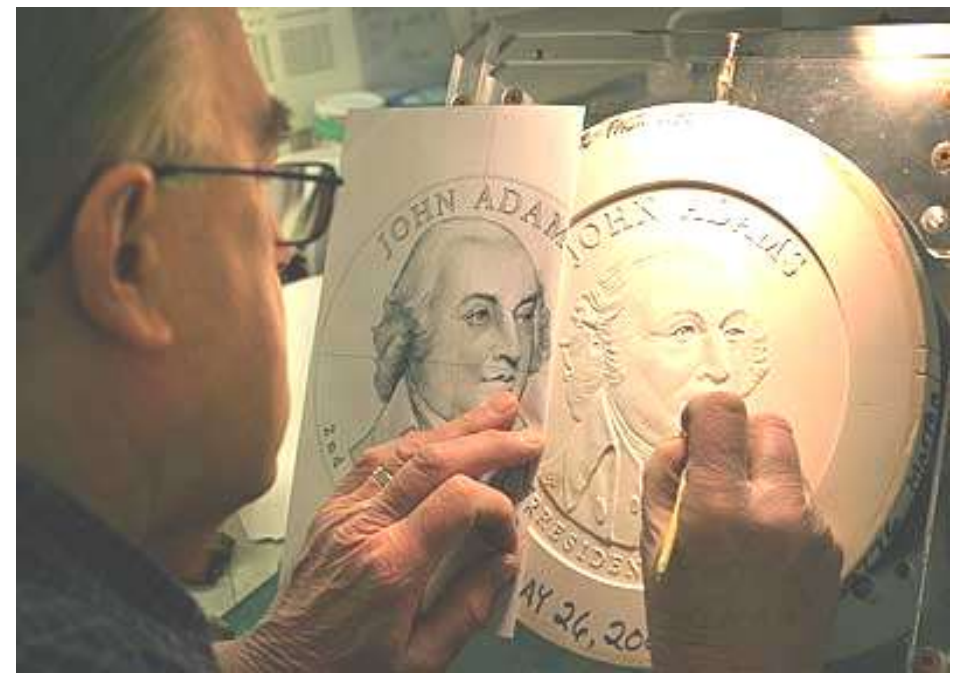

نحت نموذج المبدالية 

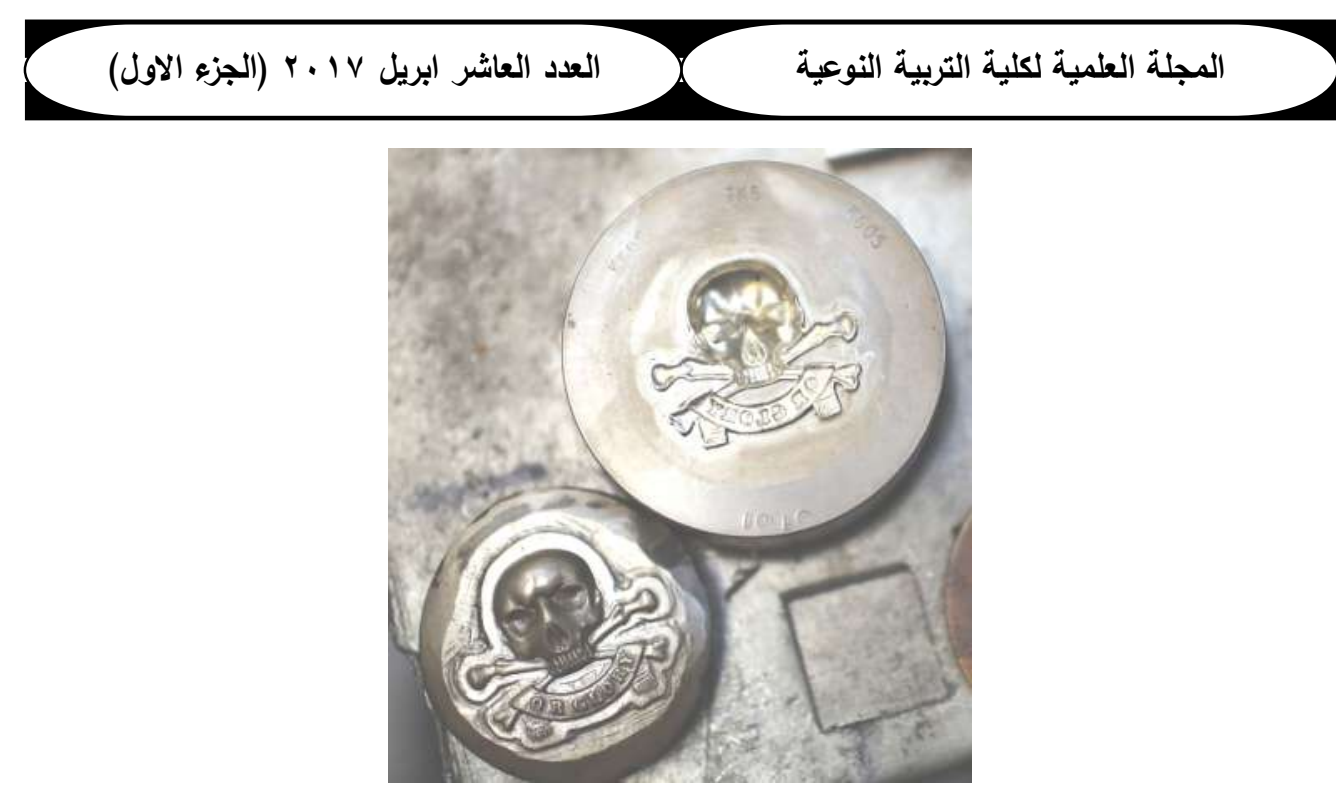

قالب دن الصلب تم حفره بماكينة البانتوجراف Pantograph
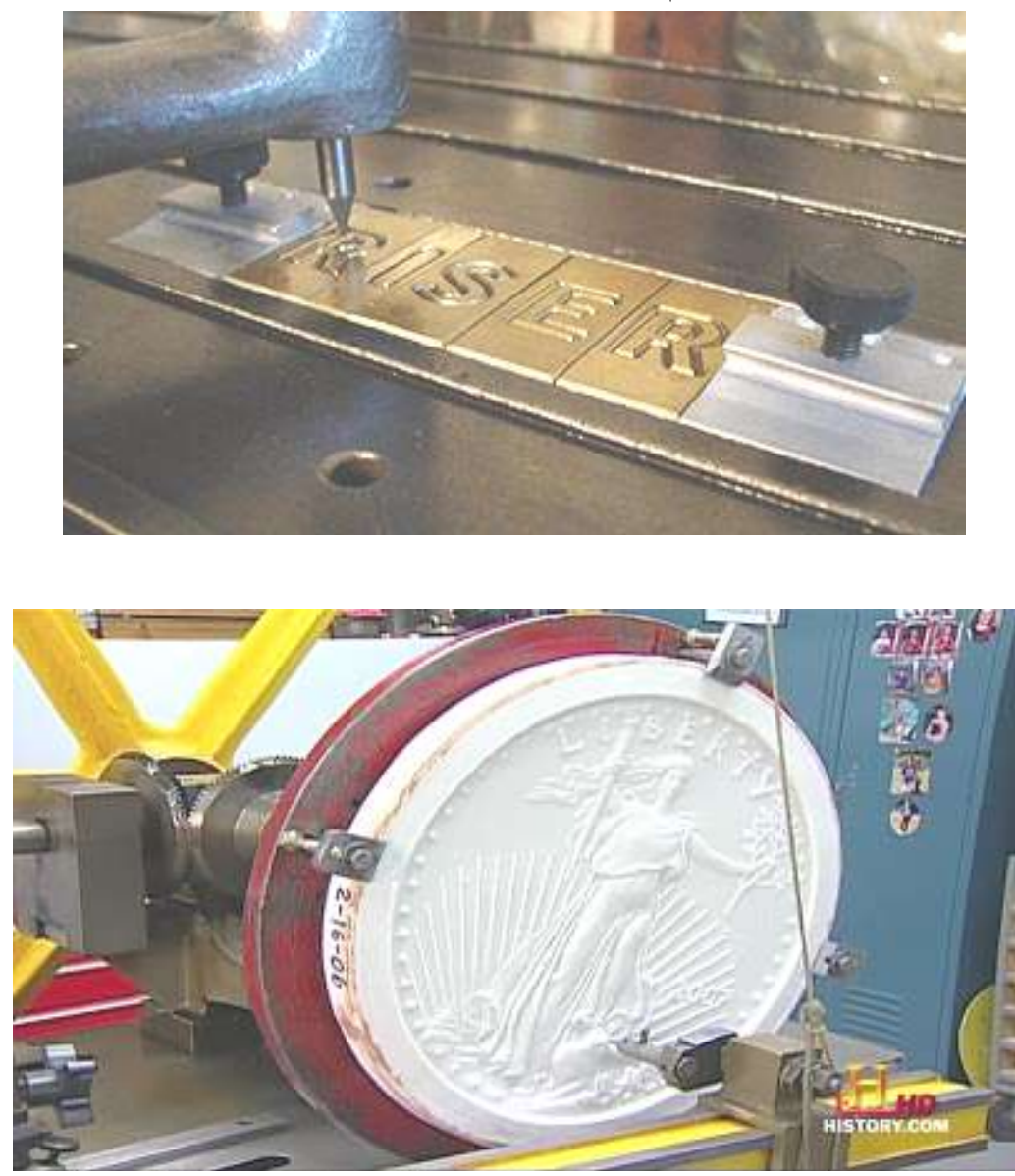

ماكينة البانتوجراف تقوم بالتكبير اوالتصغير للشكل النحتي وحفر نموذج يحاكي الاصل علي الصلب 


\section{الطباعة ثلاثية الابعاد :}

تعتبر الطباعة ثلاثية الابعاد ثورة في النتكيل النحتي، حيث تعطي المكانات واسعة

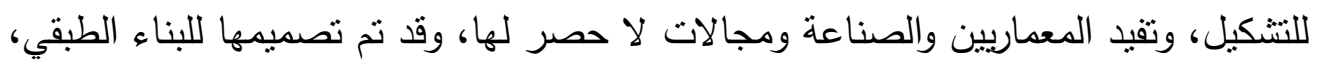



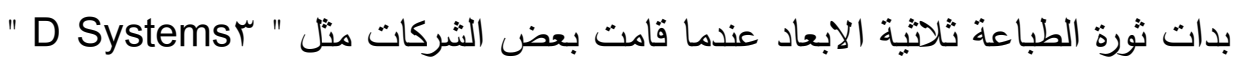


مما ساهم في تطور طباعة الاجزاء بالاعتماد علي مواد قوية جدا، يمكن استخدامها فعليا


اصبحت الطباعة ثلاثية الابعاد تستخدم في انتاج العديد من المجسمات التهات مثل قطع

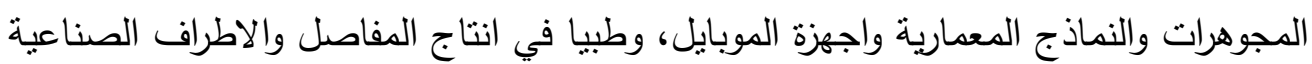
واطقم الاسنان.

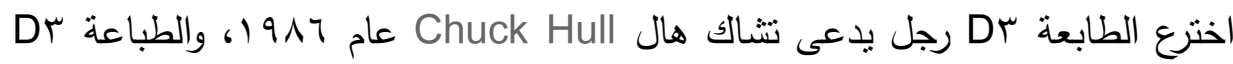
هي عملية تحويل الملف الرقمي الى كائن مادى. في حين ذهب هال هال لعرض فئ فكرته علي

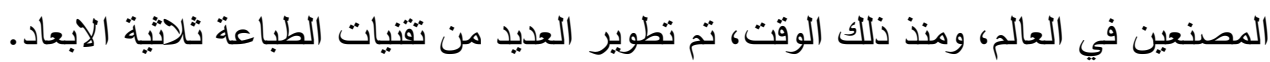

\section{هناك ثلاثة انواع رئيسية من الطابعات ثلاثية الابعاد:}

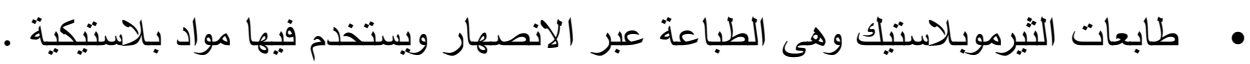


طابعات الليزر ثلاثية الابعاد وهي نتبه الطباعة الضوئية الا انها تستخدم الليزر كوسيلة

$$
\text { لتكوين الاشكال. }
$$

وهناك العديد من الاستخدامات المنطورة للطباعة ثناثية الابعاد، فقد ارسلت و كالة ناسا



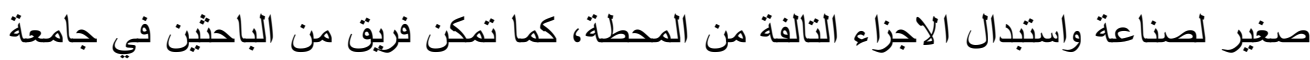

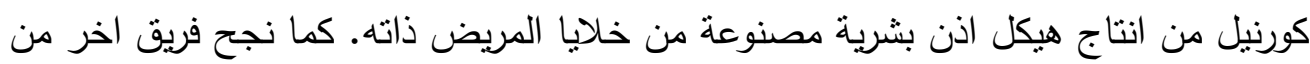

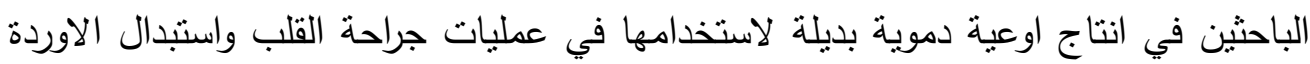

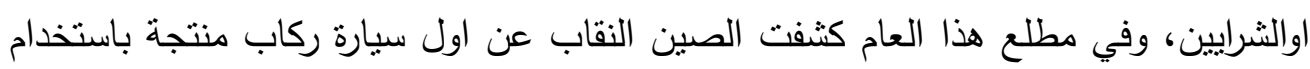

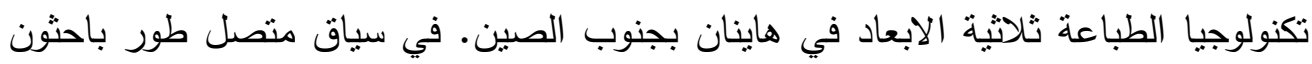



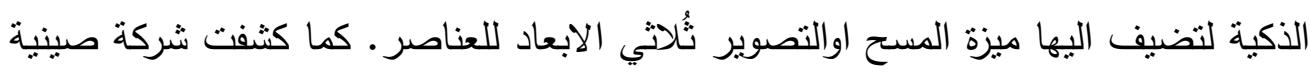


ثُدعى "وين سون” WinSunالستار عما قالت انه اول مبنى سكني منشا بتقنية الطباعة ثلاثية الابعاد، بالاضافة الى فيلا مساحتها ـ . 1, 1 متر مربع استخدم في انشائها نفس التقنية. يستخدم الجيش الاميركي عدة طابعات ثلاتثة الابعاد لانتاج قطع تبديل التجهيزات العسكرية في الميدان عند الحاجة وبسرعة فائقة.

دور الطابعة ثلاثية الابعاد فى التشكيل المعاصر :

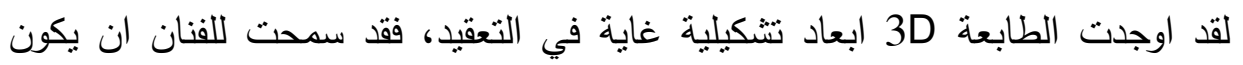

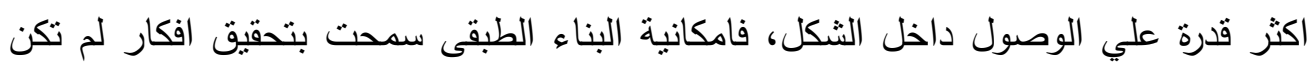



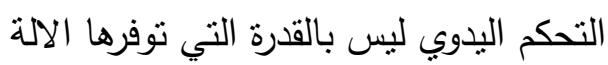

لقد اصبح عمق العمل في دائرة اهتمام الفنان، واصبح البحث عن تفالفئ تفاصيل داخلية



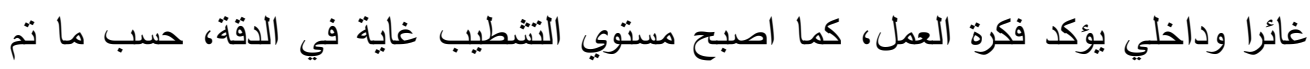

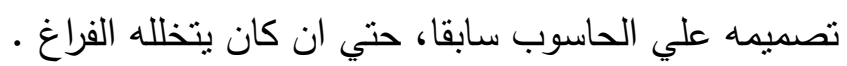





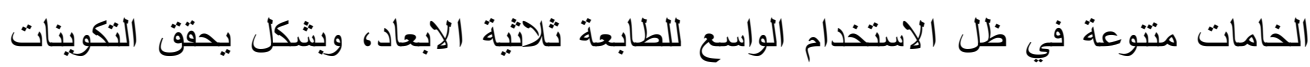

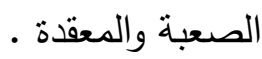
تعتبر الطباعة 3D من الانجازات العلمية المنطورة، والتي سيكون لها دور واضح في

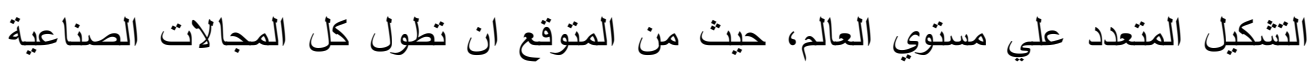

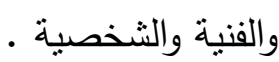



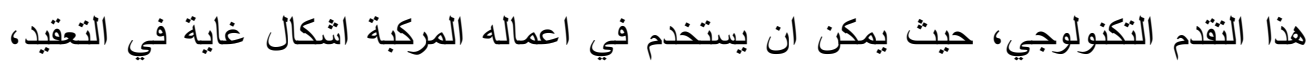



لقد امكن استخدم الطابعة فى تثكيل العديد من الخامات الاسمنتية والطينية والبلاستيكية

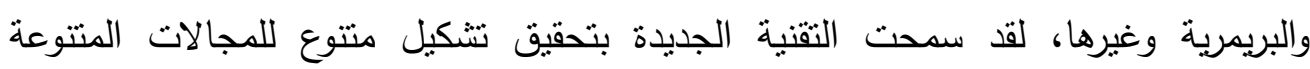
كالنحت والخزف والتتكيل الفراغي، وهو ما يتطور بشكل يومي مع المجربين والفنانين و رجال الصناعة . 


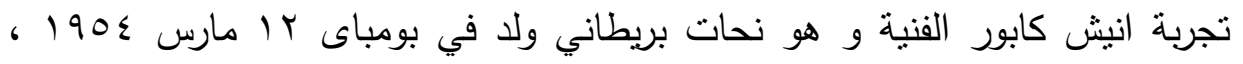



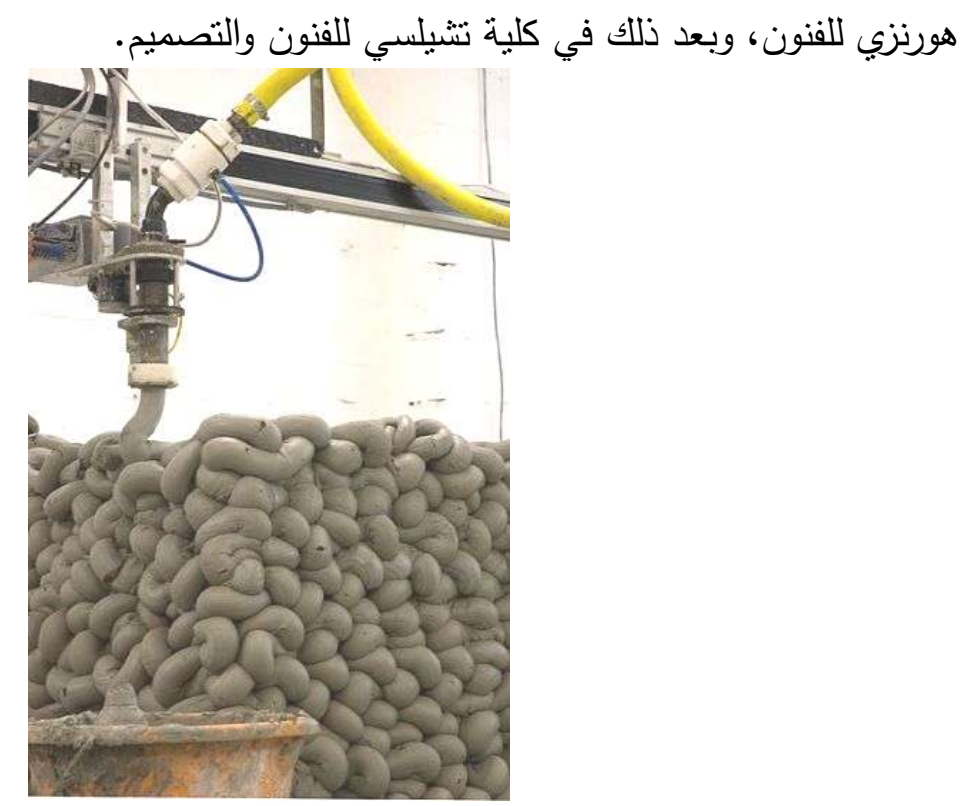

طباعة ثلاثية الابعاد باستخدام خامة الطين

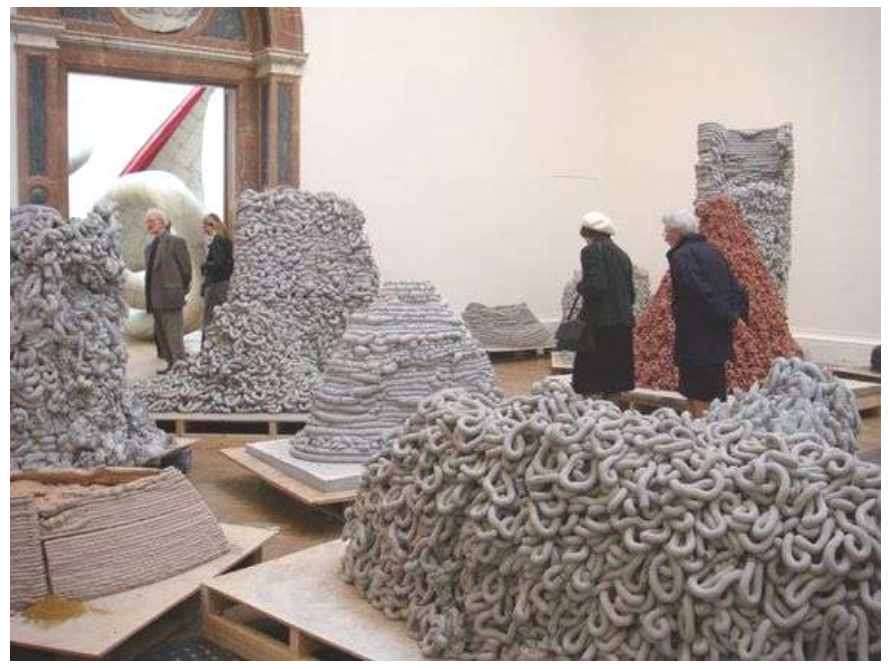

عمل للفنان انيش كابور Anish Kapoor الاكاديمية الملكية للفنون في لندن عرض انبش كابور Anish Kapoor عددا من الاعمال المميزة في الاكاديمية الملكية

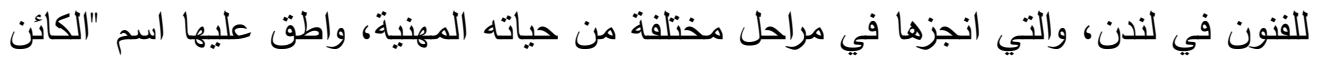




الدقة، والتي استخدم فيها الطابعة ثلاثية الابعاد والتي كانت طاغية على اللمسة الانسانية في

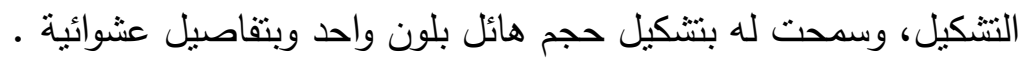



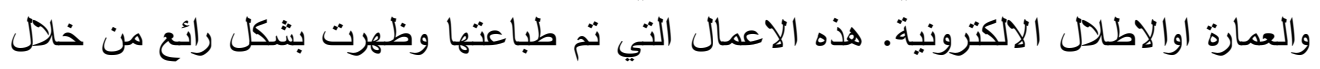



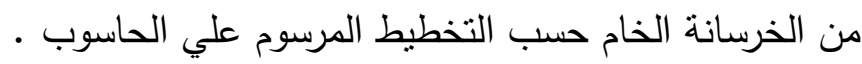



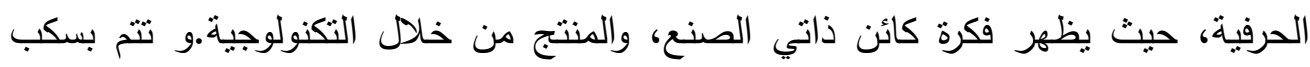


يؤدى الى تسجيل الحدث. لجعل الفن الغير يدوى هدف يضع الفن خارج التعبير، حيث يؤكد كابور حاجة الفنان

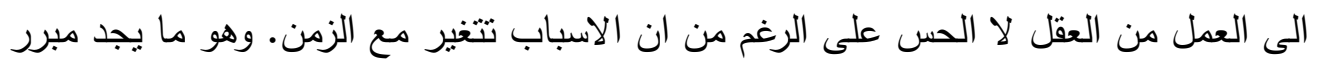


ان الاعتماد المتزايد على العمليات العلمية والصناعية اللاحقة لانتاج الاعمال الفنية

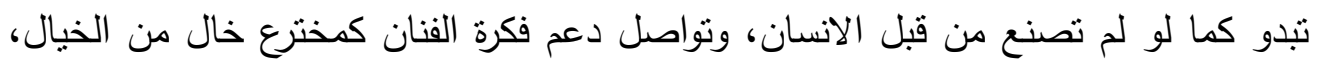





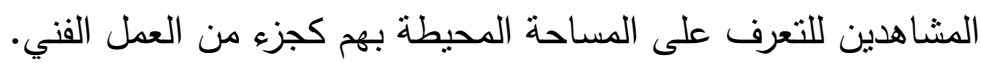



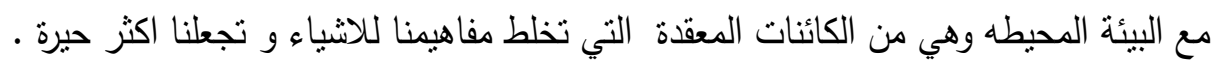
في احدى غرف الاكاديمية الملكية للفنون، قام كابور بتركيب سلسلة فلئة من الكائنات

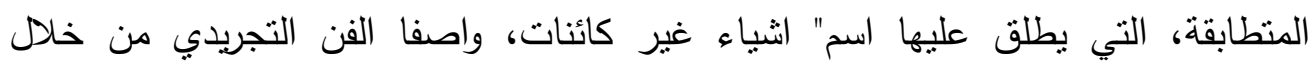



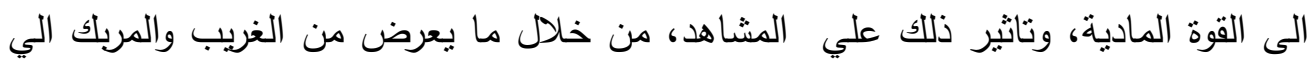
المشوش والمؤلم.

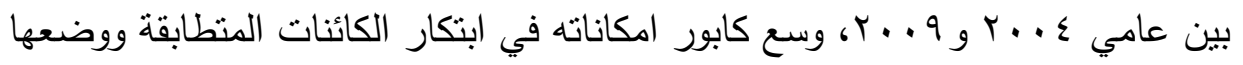

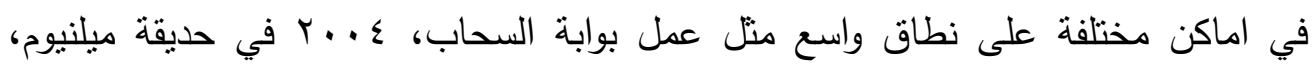






المحيط ، ويقول كابور ان هذه الاعمال نوع جديد من المغامرة المكانية لجعل الفن الجديد. 


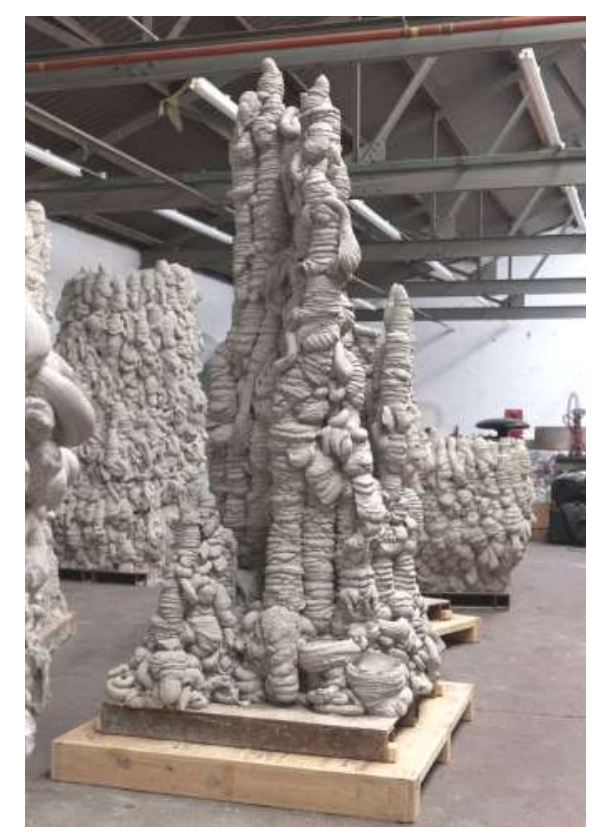

عمل للفنان انيش كابور Anish Kapoor

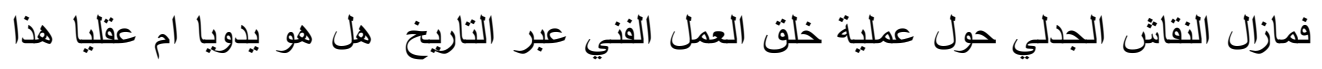





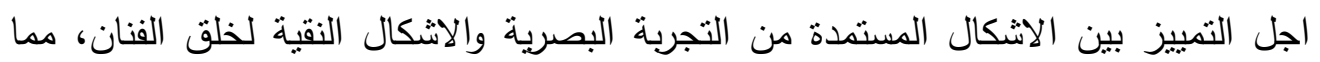

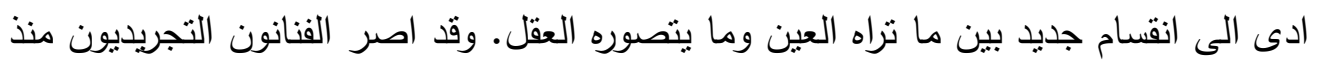

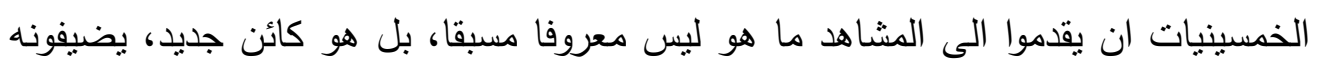


التمثيل او المحاكاه. بدا نضال الفنانين للقضاء على اي تشابه للاشياء التي بمكن التعرف عليها في فنهم "الغير



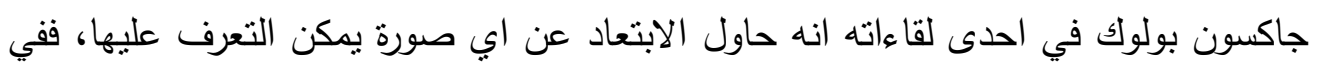

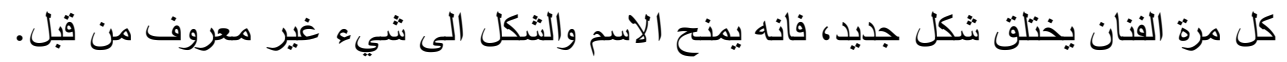





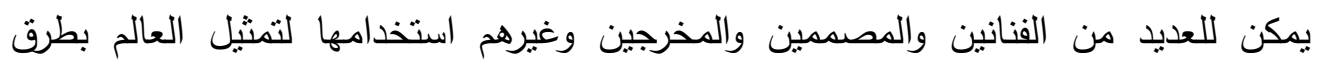
مختلفة، اي انشاء اشكال فريدة خاصة بهم تقود الي عملية تخصيب جذرية لا تتوقف ابدا. 


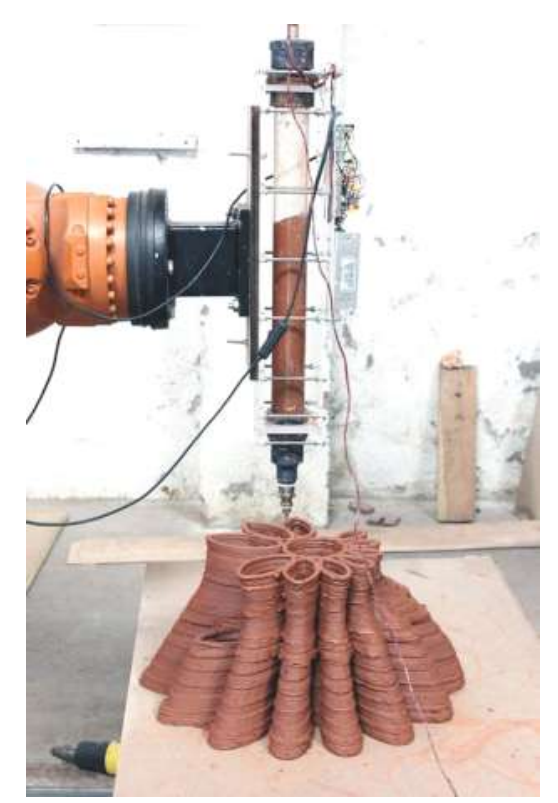

طباعة ثلاثية الابعاد من خلال تكوين طبقات من خامة الطين لتجسيم الثنكل

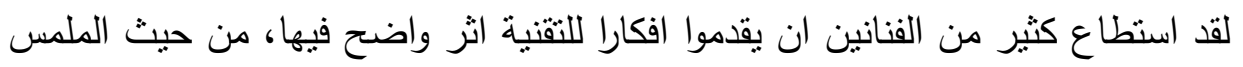
اوالانشاء اوالتكرار ، او من حيث الحلول الداخلية اوالخارجية . كما تتوعت خامة التشكيل مع تطور الات الطباعة ثلاثية الابعاد، حيث امكن بناء اثكال ضخمة تتناسب مع اتساع حجم الميكنة وهو ما نراه في اعمال انيش كابور .



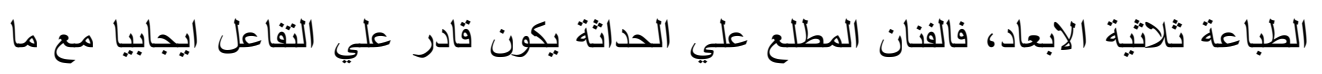

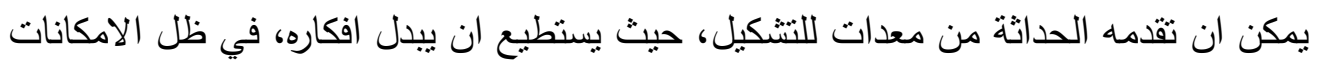




- http://aitmag.ahram.org.eg/News/20781.aspx-

- -http://www.greekarchitects.gr/en/degrees/anish-kapoor-non-objective-objects-id2609

- https://3dprint.com/82272/what-3d-printing-works-

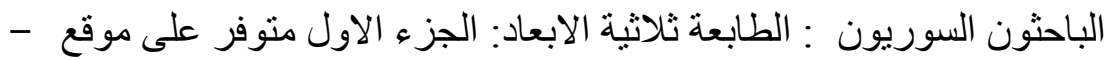
file://C:/Users/Admin/Downloads/syr_res_8208.pdf

حسن حسان : كلية المعلمين جدة متوفر علي موقع

- -213c/?com.res-syr://http 213d/?com.res-syr://h

- https://3dprint.com/82272/what-3d-printing-works/-

- http://aitmag.ahram.org.eg/News/20781.aspx-

- https://en.wikipedia.org/wiki/Anish_Kapoor-

- https://3dprint.com/82272/what-3d-printing-works/ - 